\title{
El obsceno pájaro de la noche y el absurdo en la obra de José Donoso
}

\author{
Roberto Pinheiro Machado \\ Universidad de Salamanca
}

Este ensayo analiza la estética del absurdo en El obsceno pájaro de la noche (1970), de José Donoso. La presencia de tal estética en la novela aparece como desarrollo del vanguardismo de las primeras obras del Donoso publicadas en últimos años del los 50 y en los 60. El obsceno pájaro de la noche representa la cumbre de la primera fase del autor. Allí, el discurso irracional y fragmentado producido por la mente delirante del protagonista expresa la ausencia de sentido existencial como eje fundamental de la obra.

PALABRAS ClaVE: Absurdo, vanguardia, existencialismo.

This essay analyses the presence of the aesthetics of the absurd in José Donoso's El obsceno pájaro de la noche (1970). The appearance of such aesthetic category in the autho$r$ 's novel is observed as deriving from the previous avant-garde engagements of Donoso's narrative, where experimentalism is discernible already in his early works from the late 50's and early 60's. El obsceno pájaro de la noche will appear as the culmination of Donoso's first phase, and where the irrational and fragmented discourse produced by the delirious mind of the protagonist will disclose the contradictions present in the novel as the direct expression of existential lack of meaning.

KEYWORDS: Absurd, avant-garde, existentialism.

A principios del siglo $\mathrm{XX}$ la novela hispanoamericana comienza a incorporar, de la mano de autores como Roberto Arlt, Martín Adán y Macedonio Fernández, elementos de experimentación vanguardista; sin embargo, no es sino hasta la década del ' 60 cuando este movimiento encuentra su lugar en el marco literario y crítico. La obra de José Donoso no es una excepción, y participa en la tendencia generalizada de esta década a incorporar ingredientes vanguardistas en sus novelas. Mientras en la Europa de los años veinte se producían las grandes innovaciones formales de Proust, Kafka y Joyce, en Hispanoamérica obras como La vorágine (1924), Don Segundo Sombra (1926) y Doña Bárbara (1929) significaban, como afirma Alejo Carpentier, "una búsqueda de nuestras esencias profundas".'

1 Carpentier, Alejo: Obras completas de Alejo Carpentier, Siglo Veintiuno, México, 1990, vol. 13 , pág. 225 . 
De esta forma, es posible reconocer la llegada tardía del espíritu vanguardista a la novela hispanoamericana, ya que al no abandonar las líneas realistas de la novela decimonónica, estas obras se preocupaban más por expresar la identidad hispanoamericana que por integrarse al experimentalismo característico de las vanguardias. Carpentier afirma:

La influencia del naturalismo francés, por lo mismo, se sintió en la novela latinoamericana hasta más allá de los años veinte. En cuanto a nuestro copioso "nativismo", que aún sigue vigente en ciertos sectores retardados de la literatura continental - "nativismo" que, con su descripción de ambientes y paisajes poco explotados por la literatura cobró momentáneos visos de originalidad — debemos admitir que sus mecanismos eran muy poco originales, respondiendo a una tendencia, una onda, que mucho se hacía sentir en Europa desde hacía muchos años. Fuera de casos excepcionales (...), nuestras novelas nativistas eran ecos de otras cosas que ya habían sonado en el Viejo Continente. $^{2}$

Cuando, a partir de 1960, la novela hispanoamericana tiende a incorporarse principalmente a la corriente vanguardista, su aproximación a la estética del absurdo se torna indudable, pues el absurdo, definido como la expresión literaria del sinsentido de la existencia llevada a cabo mediante el abandono del discurso lógico, o del realismo tradicional, a nivel formal, recupera en los años cincuenta gran parte de las propuestas estéticas sugeridas por las vanguardias en los años veinte y treinta. ${ }^{3}$ Siguiendo tal definición, el absurdo literario se conforma a partir de dos vertientes: una esencialmente temática, que descubre la falta de sentido vital a través de una reflexión filosófica de carácter existencialista, y otra formal, que rompe con la narrativa realista tradicional por medio de la experimentación vanguardista. ${ }^{4}$

2 Carpentier: Obras completas, pág. 15.

3 La crítica a la burguesía, la ruptura con el realismo tradicional y el experimentalismo son características de las vanguardias que se repiten en el absurdo.

4 Es necesario tener en cuenta la necesidad de la concomitancia de estos dos aspectos para una plena caracterización de la estética del absurdo. En otras palabras, no es suficiente que la obra presente una argumentación (sea a través del diálogo entre personajes o de la exposición narrativa) acerca de la ausencia de sentido en la vida, o de la esencial absurdidad de la condición humana, para que ésta se presente inserta en la estética del absurdo. Tal argumentación ubicaría el texto más propiamente en la estética existencialista. Asimismo, la presencia del vanguardismo (sea a través del surrealismo, con la invasión del estado onírico en la vigilia o de la representación de manifestaciones subconscientes como alucinaciones u obsesiones, o de otras formas de ruptura con la tradición) no garantiza la existencia del absurdo literario si ésta no apunta, a su vez, hacia el sinsentido de la existencia. Tal estética sería puramente surrealista, pero no absurda. Es importante subrayar aquí que la noción del absurdo literario proviene de una construcción crítica efectuada por Martin Esslin en su obra The Theatre of the Absurd (1961). Mi tratamiento del absurdo en la obra de Donoso busca, así, mantenerse fiel a las propuestas de Esslin. Aunque éste haya observado la estructura de la estética del absurdo en el teatro, lo que intento aquí es trasponer sus conclusiones a la narrativa. 
Analizando las características de la nueva novela hispanoamericana, Hernán Vidal subraya los elementos similares a los de la literatura del absurdo:

La nueva novela hispanoamericana, en su perfil vanguardista, ha elevado la sinceridad, el sufrimiento y la ambigüedad moral a categorías de supervivencia: sinceridad para perforar el cascarón de las falsas apariencias con que en ella se presenta el orden burgués, el sufrimiento como disciplina para encarar lo desconocido, y la ambigüedad moral para no claudicar ante obstáculos de ninguna especie, ni compromisos emocionales, en ese egreso. ${ }^{5}$

Percibimos que las tres categorías propias de la nueva novela hispanoamericana citadas por Vidal son también características de la literatura del absurdo: la sinceridad como crítica a la burguesía, el sufrimiento humano como parte importante de la reflexión existencialista acerca del sinsentido vital y la ambigüedad moral que diferencia el absurdo de la tragedia. ${ }^{6}$ Otro aspecto que aproxima la nueva novela hispanoamericana al absurdo es el uso del irracionalismo como principio narrativo. A ese respecto, Donald L. Shaw establece como una de las directrices de la nueva narrativa hispanoamericana "la tendencia a enfatizar los aspectos ambiguos, irracionales y

5 Vidal, Hernán: José Donoso: surrealismo y rebelión de los instintos, Aubi, Gerona, 1975, pág. 20.

6 El absurdo repite el humor anti-burgués de las vanguardias históricas a través de obras que presentan protagonistas marginados como Vladimir y Estragon en En attendent Godot (1953) de Samuel Beckett, las criadas que viven el rencor de su posición social desfavorecida en Les Bonnes (1946) de Jean Genet, y de obras que proponen un ataque frontal a los valores burgueses como $\mathrm{La}$ Cantatrice Chauve (1950) de Eugène Ionesco, obra a la que Martin Esslin se refiere como "an attack against what Ionesco called the - universal petty-bourgoisie... the personification of accepted ideas and slogans, the ubiquitous conformist-..." (Esslin, Martin: The Theater of the Absurd, Penguin Books, New York, 1961, pág. 140). La sinceridad como elemento primordial en la crítica a la burguesía puede ser observada en el concepto de honnêteté de Camus (Camus, Albert: Le Mythe de Sysiphe, Gallimard, Paris, 1942, pág. 39). El sufrimiento humano como parte de la reflexión existencialista está también presente en el absurdo. Uno de sus principales momentos puede ser observado en la obra L'Aveu (1946) de Arthur Adamov. La ambigüedad moral característica del Teatro del Absurdo ha sido subrayada por Susan Ann Suchman: "The sensation of endlessness and the inconclusiveness of the literature of the absurd reinforces moral ambiguity. Since tragedy is traditionally defined by the fixed moral universe in which the action occurs, the absurdist is led from his philosophical point of view to formal experimentation" (Suchman, Susan Ann: Samuel Beckett, Eugene Ionesco, and Julio Cortázar: A Study of the Absurd in Modern Drama and Narrative, University of Michigan Press, Ann Arbor, 1998, pág. 27). El propio Esslin reconoce la ambigüedad moral propia de la literatura del absurdo como reflejo de la pérdida de valores y sistemas de creencias bien definidos en el mundo moderno: "The plays that we have classed under the label of the Theatre of the Absurd, on the other hand, express a sense of shock at the absence, the loss of any such clear and well defined systems of beliefs or values" (Esslin, Martin: Absurd Drama, Penguin Books, New York, 1965, pág.12). 
misteriosos de la realidad y de la personalidad, desembocando a veces en lo absurdo como metáfora de la existencia humana"?

Dentro de esta tendencia a reflejar lo absurdo, propia de la nueva narrativa hispanoamericana, se encuentra gran parte de la obra de José Donoso. En ella encontramos las mismas influencias que Martin Esslin subraya como determinantes en Teatro del Absurdo: Joyce, Kafka y el surrealismo. ${ }^{8}$ A ese respecto, Donoso escribe en Historia personal del boom (1972):

[L]os caballeros que escribieron las novelas básicas de Hispanoamérica y gran parte de su prole, con su legado de vasallaje a la Academia Española de la Lengua y de actitudes literarias y vitales caducas, nos parecían estatuas en un parque (...) sin ningún poder sobre nosotros. Ni d'Halmar ni Barrios, ni Mallea ni Alegría, ofrecía seducciones ni remotamente parecidas a las de Lawrence, Faulkner, Pavese, Camus, Joyce, Kafka. ${ }^{9}$

Aunque la crítica no suele ser específica acerca de la relación entre Donoso y la literatura del absurdo, Selena Millares percibe la influencia de la obra de Samuel Beckett en su novelística. Subrayando la tendencia del autor chileno al irracionalismo, Millares afirma que en su narrativa "podría hablarse de un realismo alucinado, cuyas visiones de la degradación y descomposición de un mundo se alinean en el ámbito de la irracionalidad. El ascendiente beckettiano y también de Valle Inclán del esperpento tienen aquí una honda presencia". ${ }^{10}$

La influencia de Beckett y del absurdo en la obra de Donoso se hace notar más claramente en El obsceno pájaro de la noche (1970). Allí, en vez de utilizar los recursos propios de la novela realista tradicional, Donoso propone al lector una total inmersión en el mundo psíquico de Humberto Peñaloza, implicado en el caos de una personalidad enferma que acaba por perder el contacto con la realidad. Humberto Peñaloza desea convertirse en un gran escritor, pero teme que las barreras que su condición social le

7 Shaw, Donald L.: La Nueva Narrativa Hispanoamericana: Boom, Posboom, Posmodernismo, Gredos, Madrid, 1999, pág. 245.

8 En las palabras de Esslin: "There has been some comment on the fact that the Theatre of the Absurd represents trends that have been apparent in the more esoteric kinds of literature since the nineteen-twenties (Joyce, Surrealism, Kafka) or in painting since the first decade of this century (Cubism, abstract painting). This is certainly true" (Esslin: The Theatre ..., pág. 14).

9 Donoso, José: Historia personal del «boom», Alfaguara, Madrid, 1972, pág. 22.

10 Millares, Selena: “Introducción”, en Donoso, José: El lugar sin límites, Cátedra, Madrid, 1999, pág. 49. 
impone lo alejen de su objetivo. Lo que concibe como la insignificancia y ridiculez de su nombre, el apellido que cree determina su impotencia, la relación antagónica con su padre y su ineludible complejo de inferioridad hacen que Humberto entre en un mundo de fantasía donde reina la obsesión por los Azcoitía, una familia de terratenientes con gran poder político.

La relación antagónica de Humberto con la burguesía representa la crítica social, principio temático vanguardista heredado por la literatura del absurdo. Donoso, sin embargo, rechaza una posición maniquea frente al tema y presenta en su lugar el carácter contradictorio del enfrentamiento de Humberto con los Azcoitía: a la vez que rechaza sus valores, quiere ser como ellos. La imposibilidad de alcanzar un status social equivalente al de la familia burguesa lo arrojará a la locura. Como afirma Vidal: "enloquecido por las tensiones psíquicas que le provocan su sumisión a una clase que admira como paradigma de lo refinado, lo culto, lo bello - la burguesía, y su instintiva rebelión, que le exige liberarse de esa fascinación para respetar su individualidad, Peñaloza vive sus últimos años fingiendo ser sordo y mudo". ${ }^{11}$ En la esquizofrénica doble personalidad del protagonista, que es a la vez el Mudito y Humberto Peñaloza, Donoso presenta un mundo irracional en el que las categorías de individualidad, espacio y tiempo se muestran corrompidas. El absurdo aparece, entonces, a través de un discurso fragmentado donde la indeterminación y la inverosimilitud son el principio formal de expresión.

Asimismo, desde el punto de vista del contenido, el absurdo también es el principio temático de El obsceno pájaro de la noche. La existencia arrojada al sufrimiento, teñida de incoherencia y consciente de la proximidad de su fin se muestra incompatible con cualquier lógica, con cualquier contacto eficaz con la realidad. La narración delirante presenta lo irracional y lo inverosímil a través de una mirada profunda hacia el estado psíquico del protagonista, un ser ambiguo y miserable que sufre la pérdida casi total de su identidad. En su universo de horror y degradación, la violencia se inscribe en un lenguaje incomprensible que establece el absurdo como reflejo de la existencia condenada al fracaso.

Desde el punto de vista del desarrollo de la obra donosiana, El obsceno pájaro de la noche escenifica un momento de ruptura con la tradición literaria en que se incluía su novelística hasta el año 1970. A ese respecto, Pamela May Finnegan afirma:

11 Vidal, Hernán: José Donoso..., pág. 180. 


\section{ROBERTO PINHEIRO MACHADO}

Prior to 1970, Hispanic criticism principally had characterized Donoso's prose works in relation to the criollista canon of socially-conscious and socially-focused works. More specifically, as an author, Donoso was the continuer of the great Chilean social novel (...). The publication of The Obscene Bird of Night was a troublesome event in Latin American literary history as the novel presented a seemingly radical change from Donoso's previous prose output. ${ }^{12}$

El aspecto novedoso de esta obra se inserta en la nueva tendencia que amalgama forma y contenido en la expresión del sinsentido de la existencia. Toda vez que la literatura del absurdo se diferencia de la literatura existencialista por presentar la irracionalidad de la condición humana "en acto"; ${ }^{13}$ es decir, a través de principios formales que adoptan lo ilógico como medio fundamental de expresión, es posible entender la pertenencia de esta novela a la estética del absurdo.

Entre los principios formales que conforman el vanguardismo de la estética del absurdo encontramos el surrealismo como una de las principales tendencias. Estamos de acuerdo con las palabras de Susan Ann Suchman cuando afirma que el absurdo "is rooted in the philosophical observations of the existentialists and the non rational artistic ideas of the surrealists". ${ }^{14}$

La fusión entre existencialismo y surrealismo propia de la literatura del absurdo está claramente presente en El obsceno pájaro de la noche. Mientras el existencialismo se verifica en la profunda indagación acerca de la existencia humana llevada a cabo en el tratamiento de temas específicos como lo grotesco, la muerte y la incomunicación, el surrealismo se establece en el propio lenguaje que refleja el delirio, la ambigüedad y lo irracional. ${ }^{15}$ Así, a través de un análisis de las estéticas existencialista y surrealis-

12 Finnegan, Pamela May: The Tension of Paradox: José Donoso's The Obscene Bird of Night as Spiritual Exercises, Ohio University Center for International Studies, Athens, 1992, pág. xi.

13 Esslin: The Theater..., pág. 25. Esslin percibe la diferencia entre el Teatro del Absurdo y el teatro existencialista en la capacidad del primero de expresar la irracionalidad de la existencia a través de imágenes de palco concretas en las que el discurso lógico aparece suprimido, mientras el segundo se mantiene dentro de las líneas de representación del realismo tradicional.

14 Suchman, Susan Ann: Samuel Beckett, Eugene Ionesco, and Julio Cortázar: A Study of the Absurd in Modern Drama and Narrative, University of Michigan Press, Ann Arbor, 1998, pág. 17. A ese respecto, Esslin reconoce el Teatro del Absurdo en parte como la realización del surrealismo teatral que fracasó en el seno del movimiento de Breton. Para Esslin, la insistencia de Breton en la aplicación de la escritura automática como bases del surrealismo inhibió su aparición en el teatro, medio en el que una preparación anterior a la puesta en escena excluye la posibilidad de automatismo en la escritura.

15 Acerca del surrealismo en esta obra, Isis Quinteros afirma que "el lenguaje de El obsceno pájaro de la noche corresponde a la llamada 'escritura automática' de los surrealistas, como la forma más apropiada para la expresión del delirio mental del protagonista. El escribir es así como un 
ta presentadas en los temas y las estrategias retóricas de la novela, veremos que El obsceno pájaro de la noche posee íntima relación con la estética del absurdo.

Entonces, siguiendo un plan de análisis temático y formal, abordaré a continuación tres temas específicos: lo grotesco, la muerte y la incomunicación; luego, tras el análisis temático, procederé a la observación del discurso irracional como estrategia retórica que, unida a la vertiente temática, configura la estética del absurdo en la obra.

\section{Lo grotesco}

La relación de lo grotesco con el pensamiento existencialista establecida a partir del siglo XX añade una nueva significación al concepto literario, aun cuando ya estaba presente en manifestaciones muy anteriores a la aparición del existencialismo, como, por ejemplo, en la novela gótica, Lo grotesco es, ahora, una expresión de la existencia marcada por la sinrazón, por la náusea que identifica lo absurdo como elemento intrínseco a toda forma vital. Su presencia implica el desplazamiento de la figura humana hacia su condición más brutal, donde lo incongruente y lo indeseado se conciben como parte inherente de la condición humana. Como afirma Kirsten Felicia Nigro, lo grotesco "mirrors a world out of joint, where man

\footnotetext{
'dejarse llevar,' lo que permite dar rienda suelta al fondo no consciente del personaje" (Quinteros, Isis: José Donoso: Una insurrección contra la realidad, Hispanova de Ediciones, 1978, pág. 194). Además de Quinteros, diversos críticos han subrayado los elementos surrealistas presentes en esta novela de Donoso. Sergio Macías, por ejemplo, afirma que "la destreza para reflejar un mundo psicológico, especialmente en El obsceno pájaro de la noche, viene de su intimismo, de su encierro humano y de ciertas impresiones de tipo freudiano. Lo fundamental para Donoso es el tratamiento de la psiquis a través del lenguaje" (Macías, Sergio: "Reflexiones sobre la vida y obra de José Donoso", en Homenaje a José Donoso, Caja Murcia, Murcia, 1998, pág. 80). Lo esquizofrénico y lo obsesivo aparecen constantemente en la narrativa de $E l$ obsceno... a través del discurso irracional presentado muchas veces como monólogo interior. El carácter esquizofrénico del Mudito ha sido subrayado por Robert Baker: "In any event, we can safely assert that the narrator of the novel is, in a clinical sense, schizophrenic; we have also to note that he is at the same time paranoiac" (Baker, Robert: "José Donoso's El obsceno pájaro de la noche: Thoughts on 'Schizophrenic' Form", en Revista de estudios hispánicos, 26, 9, 1993, pág. 37). Finnegan afirma que "As delirium and transparency of language combine in a surrealism, the reader's problem transfers from the reception of the text to conclusions about the text. The 'surrealist' element reminds us that The Obscene Bird of Night is not mimetic reality" (Finnegan: The Tension..., pág.19). Alejándose de la concepción novelística como mímesis de la realidad, El obsceno pájaro de la noche se inscribe en la estética surrealista, abriendo espacios para el discurso onírico, irracional e indeterminado.
} 
is a displaced person, the victim of an absurd universe whose moral and social structures no longer function". ${ }^{16}$

Arrojado a una situación de deterioro físico y espiritual, el personaje grotesco adquiere el carácter irracional propio del absurdo. Su condición es ante todo incompresible, inscribiéndose en la falta de sentido presente en la naturaleza y en el destino del individuo. Así, lo grotesco verifica la noción del absurdo propuesta por Albert Camus como el divorcio entre el mundo y el hombre, la escisión entre la razón que busca comprender y el universo que es incomprensible. ${ }^{17}$

En El obsceno pájaro de la noche, las viejas que habitan la Casa de Ejercicios Espirituales de la Encarnación de la Chimba y los monstruos de la Rinconada expresan el absurdo de la condición humana a través de su carácter esencialmente incoherente. La sinrazón aparece identificada con sus deformidades, con el mal funcionamiento de sus cuerpos, con sus aspectos repugnantes y con su aislamiento físico, emocional y espiritual. Asimismo, la dimensión existencial de lo grotesco aparece en el sufrimiento que padece el individuo frente a su propio deterioro. La decadencia física y espiritual de los personajes implica una reflexión acerca del mismo sinsentido vital que reconoce Roquentin en la novela La náusea, de Sartre. Mientras en ésta las raíces de un árbol llevan al protagonista a reconocer la falta de sentido en la vida, en la obra de Donoso tal reflexión aparece en la figura del Mudito, el cual sufre su condición grotesca hasta alcanzar la destrucción total de su identidad, que se inscribe en la indeterminación característica del mundo sombrío formado por el espacio que habita: la Casa de Ejercicios Espirituales de la Encarnación de la Chimba. Espacio ambiguo que invita a la pérdida del contacto con la realidad concreta, la Casa existe originariamente en el discurso irracional que proviene de la mente esquizofrénica del protagonista, cuya personalidad se desintegra en identidades fragmentarias que expresan sus obsesiones: Humberto Peñaloza, el Gigante, la "guagua milagrosa", la séptima vieja, la gárgola y el imbunche

16 Nigro, Kirsten Felicia: José Donoso and the Grotesque, Tesis doctoral, University of Illinois at Urbana-Champaign, 1974, pág. 72. Nigro explica que el término grotesco "was coined to describe and ornamental style discovered during the excavation of ancient Italian caves during the late fifteenth century. These 'grotto' decorations were characterized by the intermingling of human and animal forms with flowers, leaves, fruit, et cetera, in a fantastic design. Hence, the identification of the grotesque with things likewise characterized by distortion, formlessness or striking incongruities" (Nigro: José Donoso..., pág. 25).

17 En las palabras de Camus, el absurdo "c'est ce divorce entre l'esprit qui désire et le monde qui déçoit, ma nostalgie d'unité, cet univers dispersé et la contradiction qui les enchaîne" (Camus: Le Mythe..., pág. 73). 
son estadios de decrepitud que asume la identidad cada vez más endeble del Mudito.

Otro espacio donde lo grotesco se establece en El obsceno pájaro de la noche es la Rinconada, un lugar habitado por individuos que presentan diversos tipos de deformidades. La Casa y la Rinconada forman, entonces, el doble espacio donde lo grotesco y el absurdo se establecen en la obra. ${ }^{18}$ Creada por Jerónimo de Azcoitía para albergar a Boy, su hijo monstruoso, la Rinconada es un ámbito que se sitúa entre lo real y lo irreal. ${ }^{19}$ Allí, lo grotesco encuentra su plena realización en la figura de Boy, que nace como víctima de una naturaleza que lo convierte en aberración. Su cuerpo es un listado de defectos físicos que lo empujan hacia la categoría de lo monstruoso. El narrador describe:

Desde el punto de vista científico, lo confirmaron los expertos, el nacimiento de Boy era una aberración: ese gargolismo que le encogía el cuerpo y le encorvaba la nariz y la mandíbula como ganchos, ese labio leporino que le abría la cara como la carne de una fruta hasta el paladar... increíble, inaceptable, dijeron los médicos, los niños-gárgola sólo viven días, cuando mucho semanas, este caso de labio leporino es inaudito, esta joroba, estas piernas, si parece que todos los defectos posibles estuvieran congregados en este cuerpo, no, usted, don Jerónimo, tiene que conformarse con la idea de que su hijo morirá, y quizás sea para mejor, imagínese el destino de un ser como éste..$^{20}$

Don Jerónimo de Azcoitía rechaza la idea de la muerte de su hijo y ordena hacer todo lo posible para rectificar quirúrgicamente los defectos

18 Acerca de la concepción espacial presente en el mundo de la ficción donosiana, Flora González Mandri afirma que "Houses in Donoso's novelistic world are much more than architectural constructs; they are living structures that protect, give in abundance, and warm the body and soul. Ultimately, they are mythic spaces that allow for growth, undergo organic changes, and retain the spirit of all those who encouraged the development of the fantastic within them" (Mandri, Flora González: José Donoso's House of Fiction: A Dramatic Construction of Time and Place, Wayne State University Press, Detroit, 1995, pág. 25). Finnegan interpreta los dos lugares como ámbitos distintos, que representan respectivamente lo sagrado y lo profano. Para la autora, "Donoso's novel is basically the 'liguistification' of two worlds: the secular and the sacred, the Rinconada and the Casa, the worlds 'outside' and 'inside,' the worlds of Humberto and Mudito" (Finnegan: The Tension..., pág. 5). La Casa mantiene una profunda relación con la iglesia local, y fue construida para recibir a la "niña beata" Inés de Azcoitía. Su propio nombre, Casa de Ejercicios Espirituales de la Encarnación de la Chimba, revela su carácter religioso, en la que realizar los "ejercicios espirituales" es objetivo básico. La Rinconada, al contrario, es un espacio donde la religión no tiene cabida. Sus habitantes andan siempre desnudos, exhibiendo sus cuerpos deformes, simulando un mundo encerrado en sí mismo donde el contacto con el exterior está prohibido, y donde la vida se desarrolla de forma secular.

19 Vidal hace un interesante análisis de la Rinconada desde el punto de vista del surrealismo, y apuntando hacia su relación con el delirio del Mudito. Según el crítico chileno, "El relato de la Rinconada se manifiesta con el segundo ataque psicótico de Peñaloza, en el último año que cubre la novela" (Vidal: José Donoso..., pág. 223).

20 Donoso, José: El obsceno pájaro de la noche, Alfaguara, Madrid, 1999, pág. 248. 
anatómicos que ponen en peligro la vida de Boy. Sin embargo, exige al cirujano que no altere su condición de monstruo, el niño vivirá en la Rinconada, lugar que su padre poblará de "personajes cuyos defectos sobrepasaban la fealdad para hacerlos ascender a la categoría noble de lo monstruoso", ${ }^{21}$ seres que sufren las más variadas deformidades, "enanos de diversos tamaños, idiotas jorobados, la mujer más gorda del mundo", ${ }^{22}$ criaturas con la cara distorsionada de narices y miembros desproporcionados. De esta forma, gracias a su vida reclusa en los límites de la Rinconada, Boy jamás percibirá su propia monstruosidad.

Con la Rinconada, Donoso realiza una inversión de categorías estéticas: en este espacio surreal, lo feo se vuelve bello, y el único ser normal que allí habita, Humberto Peñaloza, es percibido por los demás como repugnante. Asimismo, la única vez que Jerónimo de Azcoitía entra en la Rinconada, su belleza física es rebasada al nivel de lo estéticamente despreciable, su condición social de terrateniente, expresada en su figura viril y su refinamiento, pierde totalmente el valor en la casa de su hijo Boy.

A través de la inmersión en lo grotesco, y de su patente inverosimilitud, la Rinconada representa el momento más evidente del absurdo en $E l$ obsceno pájaro de la noche. Como afirma Millares, "el monstruo se vincula con las fuerzas de la irracionalidad", ${ }^{23}$ y lo irracional es exactamente aquello que aflora en el discurso teñido de locura del protagonista. Además de presentarse como absurda por relacionar aspectors surrealistas con cuestionamientos existencialistas, la Rinconada revela también el intento de crítica a la burguesía común del espíritu vanguardista heredado por la literatura del absurdo. La inversión de lo bello llevada a cabo por Donoso en la Rinconada se implica en la subversión del gusto y de los valores burgueses representados por Jerónimo de Azcoitía. Boy y sus monstruos se lanzan a la trasgresión en un ambiente casi dionisiaco que anula las reglas de conducta instauradas por el racionalismo burgués.

\section{La muerte}

Otro tema que apunta hacia el sinsentido de la existencia en El obsceno pájaro de la noche es el de la muerte. Ésta opera como núcleo central alrededor de la cual gravita la narración alucinada de la novela. La muerte

21 Ibidem, pág. 240.

22 Ibidem, pág. 244.

23 Millares: “Introducción”, pág. 54. 
aparece como punto de partida y lugar de llegada, instaurando un orden cíclico. Como afirma Mandri, al principio de la obra "Madre Benita talks about Brigida's death and Misiá Raquel prepares for her own. Further, with these conversations that anticipate death and invoke the fears surrounding the event, Donoso foreshadows Mudito's death, a death that will close de novel". ${ }^{24}$ De esta forma, el sentido de decadencia de la obra se expresa en la circularidad que se inicia y concluye con la defunción de un personaje.

Con relación a este tema, el episodio de la muerte de don Clemente es especialmente significativo. Enviado por los Azcoitía para morir en la Casa de Ejercicios Espirituales de la Encarnación de la Chimba, su agonía asume inmediatamente un carácter grotesco:

Se pasaba semanas enteras sentado en su poltrona de terciopelo mirando los naranjos del patio, tranquilo, sin pedir alimento, sin reclamar que lo limpiaran, silencioso, con las lágrimas cayéndole por la cara y empapándole la sotana como la baba de un niño empapa su pechera. Hasta que comenzó a quejarse, suavemente al principio, como un animal, como si algo le doliera, nada más, como un perro que uno acaricia cuando se queja y le pregunta qué te pasa viejo, qué te pasa, aunque uno sabe que el pobre bruto no puede contestar. ${ }^{25}$

Aquí, la muerte asume un carácter absurdo a través de la identificación del moribundo con un animal. Donoso amplía el aspecto grotesco de la agonía de don Clemente ubicándolo en una escena de trasgresión donde se profanan los espacios sagrados de la Casa:

Hasta que una tarde don Clemente derribó la puerta de su celda. Salió a recorrer los pasillos desnudo, apoyado en su bastón, y durante el rosario, con todas las asiladas reunidas, se presentó como Dios lo echó al mundo en el presbiterio, rompiendo a bastonazos todo lo que encontraba, mientras las viejas gemían y chillaban y huían escandalizadas por don Clemente desnudo que profanó la capilla, que profanó sus ojos purificados por la vejez y la miseria y el sufrimiento. Al dar un bastonazo, el anciano se cayó y se golpeó la cabeza. Yo corrí a cubrirlo con un alba. Me lo llevé a su celda, donde murió llorando de pena, mudo otra vez, un par de días más tarde. ${ }^{26}$

Donoso utiliza el desnudo como forma de reforzar el absurdo. La desnudez de don Clemente retrata su locura, y contribuye a profanar la capilla donde se encontraban las asiladas. Desde el punto de vista judeocristiano, la desnudez aparece vinculada al sentimiento de culpa por el pecado origi-

24 Mandri: José Donoso's House..., pág. 69.

25 Donoso: El obsceno..., pág. 59.

26 Ibidem, pág. 61. 
nal; tras la caída del paraíso pasa a significar impudor y falta de temor a Dios. Al carácter profanador del desnudo inscrito en la tradición cristiana, Donoso añade la dimensión de la locura, ya que la desnudez de sus personajes aparece frecuentemente en momentos de demencia, de pérdida de control mental. También en el espacio ilógico de la Rinconada, los personajes son obligados a andar desnudos. Durante el baile de máscaras de la Emperatriz, único momento en que los habitantes de la Rinconada se visten, Jerónimo de Azcoitía aparece sin vestimentas y muere experimentando la humillación frente a los demás:

[M]e reconocí monstruo retorcido en el reflejo del estanque, ellos, los demás, son seres armoniosos, espigados, regulares, yo soy el bufón de esta corte de personajes principescos envueltos en el lujo de sus vestidos, soy el único desnudo, tengo que encontrar mi ropa para cubrir mis deformidades y que así dejen de reírse de mí. ${ }^{27}$

Jerónimo de Azcoitía aparece ahogado en el estanque donde observaba su propio reflejo. El carácter absurdo de la muerte de Jerónimo se intensifica por su desnudez, la cual revela lo ridículo de su situación cuando los habitantes de la Rinconada se ríen de su cuerpo.

La muerte de Jerónimo de Azcoitía conlleva las peculiaridades del tratamiento de este tema en la novelística donosiana. En la obra del autor chileno, la muerte raramente aparece envuelta en una atmósfera pacífica, por el contrario, sus narraciones suelen detenerse en el carácter agónico y decadente de los últimos momentos de sus personajes. ${ }^{28}$

\section{La incomunicación}

La incomunicación subraya la sombría visión del mundo en la que el Mudito aparece como un ser condenado al silencio, incapaz de producir sonidos, y envuelto en una atmósfera hostil y oscura. Al igual que en las

27 Ibidem, pág. 524.

28 La muerte en Donoso suele aparecer acompañada de pánico y dolor, como en el caso de Álvaro Vives, protagonista de Este domingo: "La pobre muñeca estaba muy enfermo. Cuando por último fui, la Antonia me contó que la muñeca lloraba y lloraba, y gritaba que no quería morirse y pedía auxilio porque tenía miedo. Trataron de engañarlo. Pero jamás lo creyó, ni en la etapa final, con el cuerpo lleno de metástasis: siempre supo que su muerte se aproximaba paso a paso, y con su meticulosidad de siempre contaba esos pasos y gemía de terror al contarlos. Hasta que un día, cinco meses después de ese domingo, mi abuelo murió” (Donoso, José: Este domingo, Plaza \& Janés, Barcelona, pág. 215. La cursiva aparece en texto original). 
novelas de Beckett, gran parte de la narración de la Casa y de la Rinconada se hace a través del monólogo interior. ${ }^{29}$ Acerca del silencio en que se anega el Mudito, José Promis Ojeda escribe:

Cuando obsesionado por sus delirios de persecución [el Mudito] ingrese a la casa de ejercicios convertida en asilo de ancianas, se transformará en un imbunche real, tapiando voluntariamente todos los pasos hacia el exterior, clausurando pasillos y sumergiéndose ficticiamente en el mundo de la sordera y la mudez. Desde el silencio de su condición voluntariamente asumida, el Mudito vivirá en función de sus delirios alucinantes que reactualizan obsesivamente las historias ficticias escritas cuando era Humberto Peñaloza. ${ }^{30}$

La clausura de todas las salidas de la casa por el Mudito repite el motivo del imbunche como simbolismo de aislamiento, soledad, incomunicación y silencio. El protagonista adopta la apariencia de estar subyugado por las brujas que le cosen todos los orificios del cuerpo, transformándolo en un monstruo encerrado en sí mismo. El imbunche es incapaz de comunicarse con el mundo exterior, sólo le queda el silencio. De esta forma, el monólogo interior en que se desarrolla la narrativa en primera persona de la novela aparece como resultado de la destrucción de la personalidad presente en la situación del imbunche. ${ }^{31}$

También es importante subrayar que la incomunicación del Mudito aparece envuelta en la ambigüedad característica de la novela. Sabemos que su mudez es autoimpuesta, aunque se manifieste en determinados

29 La incomunicación en El obsceno pájaro de la noche se infiere en lo que Daniel Bell llama "la estética del silencio", la cual aparece en el decenio de 1950 y está relacionada con las obras de John Cage y Samuel Beckett: "De la sensibilidad de la década de 1950 casi se podría decir que fue un período de silencio. La obras de Samuel Beckett trataron de alcanzar el sentido del silencio, y la música de John Cage hasta intentó realizar una estética del silencio. Pero el decenio de 1960 fue predominantemente un período de bullicio. A partir del "nuevo sonido" de los Beatles en 1964, el rock llegó a tal estrépito que era imposible pensar, y ésta quizás haya sido su intención" (Bell, Daniel: Las contradicciones culturales del capitalismo, Alianza, Madrid, 1977, pág. 123).

30 Promis Ojeda, José: "La desintegración del orden en la novela de José Donoso", en José Donoso: la destrucción de un mundo, Fernando García Gambeiro, Buenos Aires, 1975, pág. 39.

31 A ese respecto, Adriana Valdés escribe: "Podemos hablar de la primera persona de esta novela, del tiempo presente, como una primera persona imbunche, un presente imbunche: ambos han perdido contacto con la referencia a un discurso como acto de comunicación lingüística. Al no existir el yo-tú, 'la relación dialéctica que engloba los dos términos y los define por relación mutua' —es decir, la base misma de la intersubjetividad - la relación con los demás sólo es cuestión de deseo y de terror. Sólo se busca la destrucción de todos los objetos del deseo - Jerónimo, Inés, Iris- y la autodestrucción, que el medio de ocultar (coser, envolver) la propia carencia de identidad. Así hay dos polos posibles: la desmembración (el robo de órganos: los demás como invasores) y la integración en la completa soledad, la autoaniquilación: el imbunche" (Valdés, Adriana: "El 'imbunche'. Estudio de un motivo en El obsceno pájaro de la noche”, en Promis Ojeda: José Donoso..., pág. 137). 
momentos como real, como, por ejemplo, cuando el personaje denominado "la Iris" lo llama y él le contesta sin que ella le pueda oír:

Te debes haber escondido un momento para engañarme, y a los tres minutos, en cuanto tranqué y me escondí, volviste a la puerta que encontraste ahora con la tranca puesta. Ni siquiera te molestaste en manipular el cerrojo. ¿Para qué, si me habías descubierto? - Mudito.

Iris, respondí. No me oíste porque mi voz no se oye. ${ }^{32}$

Comparar el silencio del Mudito con el silencio en que se anega Mahood, protagonista de la novela de Samuel Beckett The Unnamable (1955), resulta conveniente para el análisis de la estética del absurdo en la obra de Donoso. Como el Mudito, Mahood se demuestra incapaz de articular verbalmente sus pensamientos:

But I am here. So I am obliged to add this. I who am here, who cannot speak, cannot think, and who must speak, and therefore perhaps think a little, cannot in relation only to me who am here, to here where I am, but can a little, sufficiently, I don't know, unimportant, in relation to me who was elsewhere, who shall be elsewhere, and to those places where I was, where I shall be. ${ }^{33}$

Aquí percibimos que la mente esquizofrénica de Mahood opera de forma más repetitiva que la del Mudito. Su silencio refleja un estadio de deterioro mental que parece superar al del protagonista de Donoso, el cual aún es capaz de proyectar un sentido a sus elucubraciones y develar en ellas el odio y la envidia que siente por Jerónimo de Azcoitía. Finnegan subraya que el silencio del Mudito se infiere de forma más amplia en el carácter silencioso de la novela en su totalidad. Para la autora, la obra de Donoso es de hecho un "texto de silencio". ${ }^{44}$ La mudez del Mudito/Humberto Peñaloza es también parte de los ejercicios espirituales que se deben practicar en la Casa, pues, "the goal of the exercitant is to become empty of all language in order to receive God's message". ${ }^{35}$ De esta forma, el silencio se extiende a la relación entre lo sagrado y lo profano impregnado en la obra a través de sus dos espacios antagónicos: la Casa de Ejercicios Espirituales de la Encarnación de la Chimba (sagrado) y la Rinconada (profano).

32 Donoso: El obsceno..., pág. 84.

33 Beckett, Samuel: Molloy, Malone Dies, The Unnamable, Alfred A. Knopf, New York, 1997, pág. 343.

34 Finnegan: The Tension ..., pág. 20.

35 Ibidem, pág. 36. 
La destrucción total de la personalidad del protagonista conduce la narración a la nada y al silencio. Asimismo, toda vez que es autoimpuesta, la mudez aparece como algo deseado por el Mudito, algo inscrito en su impulso de auto-destrucción y que prontamente se transforma en un arrojarse al silencio. De forma similar, en The Unnamable, Mahood parece anhelar el mutismo:

\footnotetext{
But what shocked me profoundly, to such a degree that my mind (Mahood dixit) was assailed by insuperable doubts, was the suggestion that the misfortune experienced by my family and brought to my notice first by the noise of their agony, then by the smell of their corpses, had caused me to turn back. From that moment on I ceased to go along with him. I'll explain why, that will permit me to think of something else and in the first place of how to get back to me, back to where I am waiting for me, I'd just as soon not, but it's my only chance, at least I think so, the only chance I have of going silent, of saying something at last that is not false, if that is what they want, so as to have nothing more to say. ${ }^{36}$
}

Para Mahood, el encuentro con el silencio significa el encuentro consigo mismo, la llegada al lugar donde "yo me espero a mí mismo". De la misma forma, el Mudito se lanza al silencio, y lo encuentra finalmente cuando se adentra en la nada después de ser consumido por el fuego. Aquí es importante subrayar que la búsqueda del vacío por los dos personajes está teñida de autocompasión. Aunque los procesos mentales del Mudito parezcan más violentos que los de Mahood, lo cual encara su condición de forma más reflexiva, el sentimiento de pesar hacia sí mismo, es decir, el reconocimiento de su intrínseca miseria, es parte del perfil psicológico de ambos personajes. De este modo, podemos concluir que el tema del silencio aparece en la literatura del absurdo como forma simbólica del fracaso inherente al género humano. Vivir es sufrir, y frente al sufrimiento no hay otra opción que callarse.

\section{El discurso irracional}

$\mathrm{Al}$ abandonar la estructura de la narración lógica, el discurso irracional cobra protagonismo formal, y permite la realización del absurdo literario. El irracionalismo narrativo opera en diversos niveles: el de la ambigüedad, de la indeterminación, de la paradoja, de la inverosimilitud, de la

36 Beckett: Molloy..., pág. 366. 
incoherencia y del delirio. Éstos establecerán las funciones básicas de una estética que rechaza el realismo decimonónico y preconiza una visión de mundo que reconoce la existencia humana como una empresa que carece de un sentido específico.

Mientras el abandono del discurso lógico es aquello que permite que el absurdo se presente "en acto", en El obsceno pájaro de la noche tal rechazo de la lógica facilita que la narración desemboque en una forma textual donde la ambigüedad y la indeterminación se hacen presentes como reflejo directo de la carencia de sentido existencial. Acerca de los conceptos de ambigüedad e indeterminación en su relación con la novela de Donoso, en Aspectos de lo indeterminado en El obsceno pájaro de la noche, Luis A. Torres escribe:

El obsceno pájaro de la noche no es un texto ambiguo sino indeterminado. En este sentido, las interpretaciones originadas en el proceso de lectura y por la reflexión hermenéutica son propiciadas por la misma apertura del texto, pero ellas no lo cierran ni lo determinan. La ambigüedad, como el conflicto entre dos interpretaciones igualmente válidas, se puede eliminar al escogerse uno de los dos sistemas. La indeterminación, por otra parte, no puede ser superada, y ante la lectura el texto mantiene su carácter indeterminado. ${ }^{37}$

Torres diferencia los dos conceptos de forma rigurosa, ateniéndose a los matices que pueden asumir bajo una inspección minuciosa. Sin embargo, es importante resaltar que aunque no sean sinónimos, ambigüedad e indeterminación asumen una relación de orden directo. Independientemente del hecho de que sea o no superada, la ambigüedad genera siempre un cierto grado de indeterminación, y de ahí que los dos conceptos aparezcan frecuentemente unidos.

Sea como fuere, lo que nos interesa aquí es percibir aquellos momentos de ambigüedad e indeterminación en El obsceno pájaro de la noche que revelan características semejantes a las formas narrativas de la literatura del absurdo. Veamos el siguiente fragmento de la novela:

Mucho después, cuando él ya no existía, si es que alguna vez existió y todo esto no es invención mía, pude comprobar que sus obsesiones eran pura fábula, porque la gente que era alguien, la gente con rostro, era casi igual a nosotros. ${ }^{38}$

37 Torres, Luis A.: Aspectos de lo indeterminado en El obsceno pájaro de la noche, University of Toronto, Toronto, 1992, pág. 6.

38 Donoso: El obsceno..., pág. 105. 
El narrador, Humberto Peñaloza, pone en duda la existencia de su padre, a quien se refiere al principio del fragmento. Aquí opera una especie de indeterminación basada en el hecho hipotético de que su mente haya "inventado" la realidad circundante. Tal forma de indeterminación es similar a la que encontramos en el siguiente fragmento de The Unnamable, de Samuel Beckett:

No, as long as this point is not cleared up to my satisfaction, or as long as I am not distinguished by some sense organs other than Madeleine's, it will be impossible for me to believe, sufficiently to pursue my act, the things that are told about me. (...) But say I succeed in dying, to adopt the most comfortable hypothesis, without having been able to believe I ever lived. ${ }^{39}$

Aquí el protagonista pone en duda su propia existencia, la cual, para él, no puede ser justificada solamente según la percepción de Madeleine. De forma similar, su existencia parece depender de una narración, hecho que le otorga un carácter indeterminado, como vemos en el siguiente fragmento donde el protagonista cuestiona la verosimilitud de su vida:

And let us consider what really took place, if Mahood was telling the truth when he represented me as rid at one glorious sweep of parents, wife and heirs. ${ }^{40}$

Así como es posible que el padre de Humberto Peñaloza jamás haya existido fuera de la "invención" del narrador, la existencia de los hechos de la vida del protagonista de The Unnamable son cuestionados en a partir de la duda acerca de la veracidad en su representación por el propio Mahood, el cual es el mismo narrador. De esta forma, se expresa una situación de ruptura de la identidad similar a la que ocurre con el Mudito.

El lenguaje delirante del protagonista conforma gran parte del discurso irracional de El obsceno pájaro de la noche. Millares cita las palabras del propio Donoso explicando la locura de Peñaloza como resultado de los efectos de su intolerancia a la morfina:

A causa de mi intolerancia a la morfina, pasé varios días enloquecido, con alucinaciones, doble personalidad, paranoia e intentos suicidas. Cuando me recuperé se me devolvió en avión a Mallorca, pero los efectos retardados de esta locura demoraron un par de años en desaparecer (...). En un esfuerzo sin pausa durante ocho meses, todavía sufriendo de pesadillas y paranoia, empecé a reescribir desde el principio $E l$

39 Beckett: Molloy..., pág. 390.

40 Ibidem, pág. 368. 
obsceno pájaro de la noche. El recuerdo de los miles de páginas que ya había escrito dio al material una organización quizá redescubierta tras mi experiencia con la locura. ${ }^{41}$

El delirio del protagonista permite que sus obsesiones aparezcan de forma caótica en las páginas de El obsceno pájaro de la noche. Sus impulsos subconscientes afloran a la narración, estableciendo el discurso irracional como base de la obra. De esta manera, encontramos en la novela de Donoso el abandono de la lógica formal propio de la literatura del absurdo sumado al retrato de la condición existencial de los personajes. La estética surrealista se establece así, a través del discurso irracional, caótico, incoherente y delirante del Mudito, y se suma a la expresión del sinsentido de su existencia como una vida anegada en la miseria, el dolor, la incomunicación y la locura. En una palabra, a partir de la concomitancia entre estas dos vertientes se establece la estética del absurdo en El obsceno pájaro de la noche. 